\title{
Sobre a Dor e a Delícia da Atuação Psicológica no SUAS
}

On the Pain and the Delight of the

Psychological Practice in SUAS

Sobre el Dolor y la Delicia de la Actuación Psicológica en el SUAS

Alexandre Franca Barreto

Universidade Federal do Vale do São Francisco

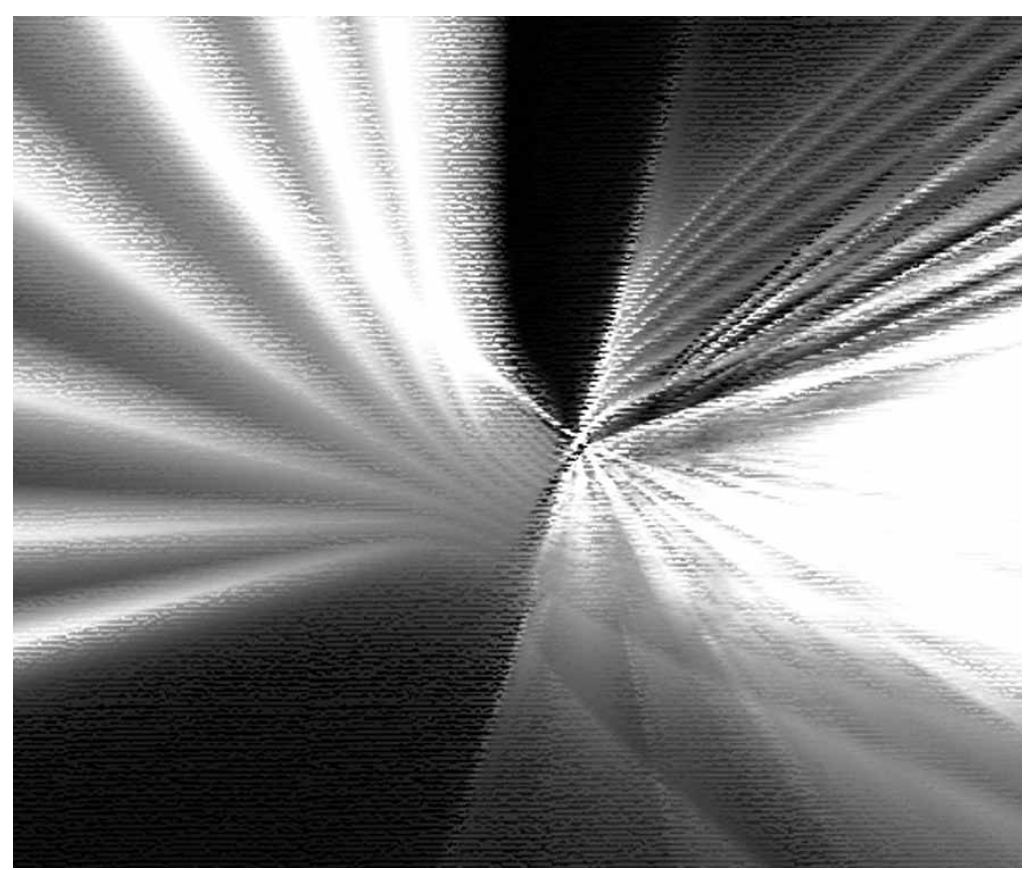


Resumo: Este artigo traz reflexões sobre o trabalho do psicólogo no Sistema Único de Assistência Social, com base em uma experiência de seis anos de atuação no campo e em pesquisa em serviços de execução de medidas socioeducativas e educação social de rua, nos Municípios de Olinda e Recife, PE. Após breve histórico de minha trajetória no SUAS, procuro contextualizar minha identidade no atual cenário éticopolítico da profissão, envolvido pelas transformações no contexto da formação e pelas tendências atuais nos cenários da prática psicológica em políticas públicas. Proponho alguns elementos norteadores do exercício profissional na lógica do pêndulo: o cuidar e ser cuidado, a agressividade e a passividade, escutar o Outro e falar de si, como polos por onde devemos transitar para desenvolver uma prática qualificada e criativa. Por fim, são apontados questionamentos sobre a dinâmica do psicólogo nos serviços de assistência social, com algumas recomendações para o suporte e a qualificação do trabalho.

Palavras-chave: Identidade profissional. Intervenção psicológica. Políticas públicas. Percepção de papel.

\begin{abstract}
This article reflects the psychologists practice in the National Unified Social Services based on an experience of six years in research and services on educational measures of street social education, in Olinda and Recife, both in Pernambuco. After a trajectory in SUAS, I intend to contextualize my professional identity in the current ethical-political scenario of Brazilian psychology, which is influenced by the transformations in the professional capacity building and the current tendencies of psychology practice in public policies. I propose some professional practice guidelines following the pendulum logic: "to take care and to be taken care", "aggressiveness and passivity", "listening to the other and talk about oneself". I suggest these edges should be experienced in order to develop a qualified and creative practice. Ultimately, some questions concerning the psychologist's practice dynamics in the social services context are asked, and some suggestions on practice qualification and support are made.
\end{abstract}

Keywords: Professional identity. Psychological practice. Public policies. Role perception.

Resumen: Este artículo trae ponderaciones sobre el trabajo del psicólogo en el Sistema Único de Asistencia Social, basado en una experiencia de seis años de actuación en el campo y en investigación en servicios de ejecución de medidas socio educativas y educación social de calle, en los Municipios de Olinda y Recife, PE. Después un breve histórico de mi trayectoria en el SUAS, busco contextualizar mi identidad en el actual escenario ético y político de la profesión, envuelto por las transformaciones en el contexto de la formación y por las tendencias actuales en los escenarios de la práctica psicológica en políticas públicas. Propongo algunos elementos orientadores del ejercicio profesional en la lógica del péndulo: cuidar y ser cuidado, la agresividad y la pasividad, escuchar al Otro y hablar de si, como lugares por donde debemos transitar para desarrollar una práctica calificada y creativa. Por fin, son presentadas discusiones sobre la dinámica del psicólogo en los servicios de asistencia social, con algunas recomendaciones para el soporte y la calificación del trabajo.

Palabras clave: Identidad profesional. Intervención psicológica. Políticas públicas. Percepcion del rol.

Este texto tem o objetivo de contribuir para a reflexão do trabalho da Psicologia no Sistema Único de Assistência Social. Nesse foco, escrevo com a experiência de seis anos trabalhando e pesquisando a política de assistência social. Tal trabalho afirma a pertinência de comunicar e refletir sobre os meandros de nossa labuta, diante da fragilidade de nossos vínculos profissionais, dos dilemas éticos, bem como do encontro com a alteridade presente nas vidas massacradas pela experiência de exclusão social.

Deixando de lado a busca por uma nova tecnologia social em nosso trabalho, proponho-me a pensar sobre simples posturas, atitudes e flexibilidade de papéis e espaços que podem ofertar uma qualificação e um fortalecimento da nossa atuação.

A linguagem para esta comunicação é a autoetnografia, que integra a experiência pessoal, profissional e política em uma única performance crítica, elegendo o corpo como lócus de consciência acadêmica e alfabetização profissional. Essa forma de expressão tem sido protagonizada nas últimas duas décadas pelos estudos e relatos qualitativos no campo das ciências sociais, com destaque na Antropologia pós-estruturalista (Reed-Danahay, 1997; Spry, 2001). 
Compreendo esse método como recurso singular na comunicação das tramas da vida profissional, em meio às inúmeras demandas políticas, subjetivas, institucionais e coletivas que recheiam o cotidiano isolado de cada um dos colegas com quem pude qualificar minha prática ao longo desse tempo. A esse respeito, Spry comenta:

Os textos autoetnográficos revelam as fraturas, suturas e costuras de autointeração com os outros no contexto de pesquisar a experiência vivida. Na interpretação autoetnográfica do texto, os leitores sentem/ percebem as fraturas em suas próprias vidas comunicativas e, como a noção de Gramsci do intelectual orgânico, criam eficácia e curam em suas próprias vidas comuns (Spry, 2001, p. 712 - tradução livre).

Minha trajetória iniciou-se no último ano do curso de Psicologia: estagiei no Programa de Execução de Medidas Socioeducativas em Meio Aberto no Município de Olinda, $P E$ - à época o único serviço municipal de atendimento, em meio aberto, a adolescentes em conflito com a lei no Estado de Pernambuco. Durante esse período, participei de debates sobre a construção da Política Nacional de Assistência Social (2004) e envolvi-me nas primeiras discussões sobre a implementação do Sistema Único de Assistência Social (SUAS) através das Conferências (municipais, estadual e federal) ocorridas em 2003.

Favorecido por esses encontros com as políticas públicas, convivi com inúmeros adolescentes e seus familiares, conheci seus dramas e suas histórias recortadas pela violência institucional, deparando-me cruamente com o sofrimento psíquico em tessituras sociais, comunitárias, econômicas e subjetivas. Realizei meus primeiros trabalhos no território na periferia da cidade: fiz atendimentos em domicílio, acompanhei a construção de projetos de vida bem como a morte de alguns dos adolescentes e de membros de sua família.

Foi meu primeiro olhar para as demandas da Psicologia em seu encontro com os desafios sociais e humanos de nossa nação. Ainda me lembro de alguns sonhos que tinha naquela época, que refletiam o nível de stress e de frustração que muitas vezes acompanhava meu fazer profissional e que ofuscava, por vezes, a conquista do trabalho cotidiano na instituição.

Assim que me formei, em 2004, fui contratado como profissional pelo mesmo serviço em que atuava como estagiário. Acompanhei uma equipe de psicólogos que realizava o trabalho do Banco Social em Psicologia (iniciativa proposta pelo Conselho Federal de Psicologia), em uma experiência de intervenção grupal com adolescentes em conflito com a lei. Essa experiência chegou a ser relatada na II Conferência Nacional de Psicologia e Políticas Públicas, realizada no ano 2005, em Salvador, BA.

Nessa época, ingressei no mestrado, realizando por dois anos uma pesquisa etnográfica de acompanhamento a alguns adolescentes egressos do Sistema Socioeducativo (Barreto, 2007). Após esse período, fui convocado para assumir o cargo de psicólogo no Instituto de Assistência Social e Cidadania do Recife (IASC) - uma autarquia ligada à Secretaria de Assistência Social, responsável pela execução dos serviços de média e alta complexidade do SUAS. Fiquei vinculado ao Serviço de Educação Social de Rua, realizando intervenções em locais públicos, com pessoas que estavam em situação de rua, e permaneci dois anos nessa função.

As reflexões trazidas neste texto se referem às experiências e indagações alimentadas pela ação profissional: ora são comentários da superfície, do momento atual, ora da profundidade, uma espécie de eco que acompanha minha jornada profissional no campo da assistência, operando identificações e críticas, visando ao amadurecimento e ao fortalecimento da prática psicológica no SUAS.

Somos privilegiados por habitar um campo de trabalho em institucionalização e, com isso, 
carregamos os ônus e os bônus de um espaço que se encontra nesse processo. Nestas linhas que se seguem, procuro traçar o cenário de minha subjetividade profissional; em seguida, relato algumas referências aprendidas no fazer; por fim, problematizo as condições de trabalho e os impactos desses elementos na efetividade de nossas práticas, sugerindo ações que potencializem a práxis cotidiana em consonância com a implementação das políticas de assistência social.

\section{A subjetividade profissional: formação, tendência e desafios atuais}

Nas últimas décadas, acompanhamos a institucionalização crescente do que podemos chamar de psicologia engajada como uma exigência ética e um critério de qualidade na intervenção (Bock, 1999, 2003; Dimenstein, 2001), protagonista de significativas reformas em nível de formação acadêmica, produção científica e atuação profissional. Um exemplo disso é o Curso de Psicologia da Universidade Federal do Vale do São Francisco, do qual atualmente sou docente. Seu projeto pedagógico é todo direcionado para as demandas sociais, incluindo disciplinas de Psicologia e políticas públicas, bem como diálogos com o SUS e outros sistemas e serviços nos quais o psicólogo tem se inserido nos últimos anos, situação bem diversa da minha formação há menos de uma década. Contudo, estar no serviço público não significa fazer uma psicologia engajada, pois temos muitos desafios no campo da formação e prática profissional para consolidar uma práxis pautada nos direitos humanos, na autonomia dos sujeitos e na justiça social.

Esse redirecionamento científico-profissional da Psicologia implica, como estrutura originária, uma revisão ético-política de envolvimento com as transformações locais e globais que visam à justiça social, à cidadania, aos direitos humanos e à igualdade na diferença, contribuindo institucionalmente para o combate às diversas formas de violência; explicita também o compromisso de enfrentamento da miséria humana, entendendo o sofrimento subjetivo enraizado nos conflitos emocionais, sexuais, políticos, sociais e econômicos.

Essa compreensão influenciou profundamente minha formação e campo de atuação profissional. Através do Sistema de Conselhos Regionais e Federal de Psicologia, por alguns de seus representantes (em diversas gestões: 1998-2001, 2001-2004 e 2004-2007), acessei a prática política associada aos estudos que fundamentavam a Psicologia na linha de frente dos desafios sociais. Nessa práxis, encontrei também contribuições em diversos outros pesquisadores e publicações ligados à ABRAPSO (Associação Brasileira de Psicologia Social), que me abriram um vasto campo de possibilidades e desafios.

Em estudos no campo das ciências sociais, da saúde coletiva e da teoria reichiana, senti-me amparado em vários dos questionamentos que fazia. A vivência com as políticas públicas e com os movimentos sociais possibilitava contínuas aprendizagens, esclarecendo as demandas de trabalho que emergiram fortemente nos últimos anos para a nossa profissão.

Se, por um lado, essa psicologia engajada trouxe uma alternativa para a atuação profissional com minorias destituídas de direitos, por outro, ela instaura uma nova forma de ser da Psicologia, com os desafios e as problemáticas necessárias a uma práxis de ação-reflexão inerente à prática psicológica imbuída dos parâmetros ético-profissionais.

Assim, ao final de 2008, um dos grandes questionamentos da ABEP (Associação Brasileira de Psicologia) era a efetividade metodológica da prática da Psicologia desse discurso engajado e de seus delicados enlaces com um fazer generalizado dos profissionais que atuam na área social, destituído da singularidade da prática psicológica. 
Um exemplo dessa preocupação manifestouse na cartilha Parâmetros para atuação de assistentes sociais e psicólogos(as) na Política Nacional de Assistência Social, elaborada pelos Conselhos Federais de Serviço Social e de Psicologia (2007). Outro exemplo foi o trabalho desenvolvido pelo Programa Banco Social de Serviços em Psicologia e o seu desdobramento no CREPOP (Centro de Referência Técnica em Psicologia e Políticas Públicas), com pesquisas de mapeamento e sistematização de referências para o trabalho do psicólogo em diferentes campos de atuação, voltadas para as novas demandas nos serviços públicos. Dentre essas pesquisas, algumas foram realizadas no âmbito das políticas de assistência social. $\mathrm{O}$ VII Congresso Nacional de Psicologia teve um eixo específico para tratar da construção de referências e estratégias de qualificação para o exercício profissional.

De forma imanente a essas questões, produções sobre a contemporaneidade do trabalho clínico intensificam a reflexão sobre a sua mobilidade, estilos de intervenção, complexidade de contextos e cenários de atuação, assim sobre como a profundidade de elementos inseridos na dinâmica das intervenções em espaços públicos e domicílios e a interação entre as dimensões sociais e subjetivas. Esse olhar vem sendo nomeado ora como nômade, ora como social, ou ainda, ampliado, principalmente nos trabalhos que remetem o psicólogo ao contexto dos serviços públicos de saúde, mas também podemos aproximá-lo do contexto do SUAS (Rolnik, 1997; Silva, 2001; Dutra, 2004; Mazza, 2009).

Nesse espaço teórico-prático da Psicologia, vivemos a renovação do fazer-poder profissional aliado às demandas emergentes (neste caso, em especial, do SUAS), dentro de um cenário que está potencialmente disponível para novas abordagens psicológicas pautadas nos direitos humanos, carente de metodologias que produzam respostas efetivas e preocupado com a regulação de referências mínimas para o exercício profissional.
Como esses elementos operam no cotidiano do psicólogo lotado em um serviço de assistência social municipal? Que elementos podem contribuir para o avanço da atuação profissional e, em consequência, da atenção aos sujeitos da política?

São essas as perguntas que servem de referência para os comentários que se seguem neste texto. As respostas não acabadas explicitam posições e sugerem intencionalmente alguns questionamentos que possam contribuir para o fortalecimento do trabalho.

\section{Elementos e alimentos norteadores para a nutrição profissional}

Nossa alimentação deve combinar nutrientes e balanceamento sob pena de, ao errarmos algumas dessas dosagens, gerarmos prejuízos à nossa saúde. As fontes de energia para nosso corpo servem aqui como analogia para refletir sobre dois elementos necessários e contínuos em nosso fazer psicológico, como um pêndulo que, em seu ápice energético, consegue ir para ambas as extremidades, extraindo o necessário para manter-se com vitalidade, prazer e criatividade.

Para o exercício da profissão na assistência social, proponho algumas extremidades que devem interagir: o cuidar e ser cuidado, a agressividade e a passividade e escutar o Outro e falar de si. O cuidar, a agressividade e o escutar o Outro são os nutrientes que dão sabor ao nosso fazer profissional, imprimindo as doses de vitamina que estimulam o trabalho, o conhecimento e o nosso próprio desenvolvimento humano - nessa disposição para o outro, recebemos do ambiente a carga das histórias subjetivas e sociais que nos fazem avançar em nossa práxis.

O ser cuidado, a passividade e o falar de si são o balanceamento necessário para integrarmos nossas experiências, maturarmos o sabor da diversidade de elementos que 
as compõem; são base para nossa ação prudente. Esses fatores explicam nossa afetação e vulnerabilidade às atrocidades que combatemos na linha de frente.

\section{Cuidar e ser cuidado}

O cuidar e o ser cuidado são movimentos básicos da vida: não há sujeito no mundo que sobreviva e se desenvolva sem experienciar essas duas posições nas relações com o outro. Sem dúvida, há profundas variações no cuidar e ser cuidado. São evidentes os limites ecológicos, subjetivos, econômicos e sociais que recortam essas dimensões. Contudo, corroboro a defesa de Boff (1999) sobre a ética do cuidar como um mito instaurador de nossa existência, responsável pelo regimento de nossas vidas. A confirmação da Psicologia como profissão da saúde na legislação federal ratifica nossa condição de profissão do cuidado.

Nesse sentido, refletir sobre o cuidado como práxis integral refere-se a uma transformação do modo de agir profissional, afastando-o da referência da intervenção para aproximá-lo da noção de cuidado, proporcionando encontros dialógicos que estimulem a autonomia e a singularidade (Guizardi \& Pinheiro, 2008).

Há inúmeras iniciativas e provocações nas arenas de trabalho sociais que alimentam a bandeira do cuidar do cuidador - um consenso como concepção, porém muitas vezes esvaído na prática. O cuidar reforça a disposição íntima da profissão, que oferece suporte à subjetividade que nos demanda; já o ser cuidado afirma nossa semelhança humana, o encontro na mobilidade das relações, nossa coerência interna com o serviço que ofertamos e as necessidades de amparo da subjetividade para dar conta das manifestações de sofrimento que a contemporaneidade manifesta.

Conseguir viver profissionalmente esses dois lugares do pêndulo, de forma fluida e integradora possibilita a expressão da humildade na clareza de nossos limites e uma aproximação sincera com o público atendido. É evidente que o trabalho de campo do psicólogo no SUAS só é possível com cuidado na relação. Para penetrar em bairros reconhecidos pela violência e pela criminalidade, assim como no território da violência subjetiva sem prejuízos físicos e psíquicos, só é possível cuidando e sendo cuidado.

Um pequeno exemplo pode auxiliar na compreensão dessa reflexão. No início de minha experiência prática no Serviço Social de Educação de Rua, onde atuava em território (pelas ruas e praças públicas do centro do Recife), eu tinha o objetivo inicial de vincular-me com as pessoas em situação de rua e de qualificar suas demandas. Não tardou para me aborrecer com José (um dos usuários atendidos), pois logo descumpriu um de nossos acordos. Corroborando esse sentimento pessoal, percebi como eram habituais a chateação e o desapontamento de todos os profissionais daquele serviço relativo aos nossos assistidos. Que bom reconhecer minha humanidade, mas também como foi desagradável perceber a limitada tolerância para lidar com as estratégias de vida daquele público!

Em um momento de estudo de caso na supervisão, relatei o aborrecimento que tive após meu encontro com José, pois havia lhe oferecido um espaço de escuta e cuidado, que ele aceitou de início, mas, em nosso segundo encontro, ele preferiu beber a participar do momento. Minha resposta literal para José, diante desse episódio, foi: "Procure sentir se você precisa de ajuda!" Com isso, eu tentava chamar a atenção para sua indisciplina, sem reconhecer a autonomia de sua escolha e minhas limitações no manejo de sua subjetividade.

A supervisora respondeu meus comentários questionando minha postura: "E você não precisa da ajuda dele para fazer seu trabalho?" 
Foi aí que percebi o pedestal em que me encontrava, apesar de sentar habitualmente no chão das ruas.

Apesar do golpe narcísico que essa situação representou, também trouxe um alívio para meu self - percebi que, estabelecendo uma postura autêntica e reconhecendo minhas limitações pessoais e profissionais, poderia vincular-me a ele desprovido da máscara da vaidade profissional e do poder arbitrário que rotula os problemas sociais e, com isso, estabelecer relações mais profundas e verdadeiras.

Mesmo diante dos limites que tivemos, nossa relação foi gerida pela potência desse insight originário, o que proporcionou momentos de intimidade estruturantes. Ao longo de meu trabalho com José, pude acompanhá-lo em visitas à sua cidade natal, em reencontros com alguns de seus familiares bem como apoiá-lo em atividades produtivas que the proporcionaram renda e melhoraram sua qualidade de vida. Além disso, em vez do aborrecimento, o sentimento que guardo quando recordo nosso trabalho é de profundo respeito e afeto pela oportunidade de trabalhar com ele e de contribuir com sua vida.

A ajuda sentida como verdadeira é cuidado, assim como o pedido sincero de ajuda é uma demanda de ser cuidado. Isso nos coloca em uma posição semelhante e destitui a relação de poder, instaurando formas terapêuticas de vínculo. E foi justamente pelo cuidado recebido dos usuários, do vínculo constituído, que tive minha integridade física preservada, mesmo transitando por locais onde a violência física, os assaltos e tantas outras agressões aconteciam continuamente, sendo, em alguns casos, eles próprios os autores dessas práticas.

\section{Agressividade e passividade}

Como sugere Lowen (1984), a agressividade e a passividade são polos da mesma expressão. Diferente da atividade, que está presente em ambas as situações, a agressividade sugere uma energia interna para a ação, que envolve a criatividade e as demandas situacionais e que não deve ser confundida com a raiva. A raiva pode manifestar-se tanto agressivamente (através da ira, em atos de violência física e verbal) como passivamente (através do medo, como a dependência de substâncias psicoativas e o autoflagelo).

A agressividade deve existir para expressar os afetos, os sentimentos fortalecedores de vínculos terapêuticos, para agir em ações comunitárias e atividades domiciliares. Enfim, a atitude ativa de externalizar ações e sentimentos que povoam a subjetividade do profissional é elemento indispensável para a circunscrição de sua identidade, da delimitação do trabalho e da íntegra presença diante das demandas. A agressividade é necessária para formular estratégias de ação, para ousar diante dos desafios cotidianos, para se expor nas relações instauradoras da práxis; é o nutriente produzido pelo nosso saber-fazer, uma forma necessária de contestar opiniões e de firmar nossas posições éticas e políticas.

Do outro lado do pêndulo, a passividade possibilita a sabedoria de estar a um passo atrás de nossos usuários, permitindo que o desejo e a autonomia (em algum nível) sejam o norte das intervenções. Muitas vezes, é angustiante ver o sofrimento com a clareza da profundidade que habita as histórias singulares dos usuários que acompanhamos. Já acordei em noites chuvosas pensando se alguns deles conseguiram se abrigar.

Contudo, a experiência também mostrou que, nas vezes em que fui à frente do usuário em vez de exercitar a passividade e de respeitar o tempo subjetivo, as ações se evaporaram, sem sólidas raízes para a sustentação da mudança. Era comum levar os usuários para a casa de familiares, conseguir atividade remunerada ou benefícios temporários, tratamentos de saúde, e essas oportunidades passarem sem aproveitamento, com a manutenção do quadro situacional anterior. 
A passividade é o silenciar necessário para responder com assertividade, pausa indispensável à prática reflexiva e transformadora, à solidez da refutação das ações mecânicas e reprodutoras, assim como o respeito à individualidade do sujeito e a resignação ante os de nossa condição profissional.

\section{Escutar o Outro e falar de si}

O que é escutar a subjetividade de uma pessoa em situação de vulnerabilidade social? É colocar-se disponível, ouvir suas palavras, observar os seus gestos e expressões, ver o seu corpo, as marcas da vida, penetrar em seus olhos e doar-se para o encontro, permitir-se sentir pelo outro o que não lhe foi permitido nomear com clareza, compartilhar das dores, sofrimentos e conquistas da caminhada. As memórias geralmente são investidas de recordações difíceis, dolorosas, nas quais a violência esculpe as molduras atuais; o ressentimento, a mágoa e a revolta endossam a dura relutância da vida em repetições transgeracionais.

Assim, o profissional tem o desafio de dosar os sentimentos compatíveis com o vivido, porém embolados no saco da vida em decomposição, algo que é muito difícil e a que por vezes falta clareza. Há situações em que precisamos ir com nossos usuários adiante do que é falado no cotidiano, do que é visto sobre sua condição na sociedade; temos que acompanhá-los nas horas de maior exposição e fragilidade, quando suas feridas guardadas arduamente são ligeiramente expostas, já que existe o medo de retraumatizá-las.

Voltando à metáfora alimentar, a superdosagem de nutrientes sem o devido balanceamento produz um desequilíbrio: o corpo não acompanha o aumento de nutrientes, e o excesso de processamentos que devemos fazer para acomodá-los em nossa experiência gera uma estafa. Em nossa realidade, o excesso de envolvimento nas situações de campo sem o devido balanceamento de tais vivências produz uma sobrecarga emocional que continuamente se reverte em stress, frustração, episódios depressivos e tantos outros sintomas comuns em profissionais que atuam na área social (nossa condição de psicólogos/as nos expõe continuamente a esses sofrimentos ocupacionais).

Já o balanceamento em excesso, desprovido dos nutrientes necessários, empobrece a atuação profissional, amplia o distanciamento entre o psicólogo e os sujeitos da política, produz conhecimento estéril, leis idealistas e pouco efetivas, sem o devido impacto nas intervenções da Psicologia. Não há o mínimo de substância nutritiva, e isso produz uma ilusão em nossa mente, fragilizando nosso corpo, que não encontra a nutrição básica para sua atividade plena.

Na minha trajetória, vivenciei o pêndulo de ambos os lados, quando na execução direta. Como técnico do serviço, tinha muitos nutrientes, mas pouco balanceamento, o que favoreceu a vivência de episódios depressivos, de experiências de frustração e de contínuo stress, com uma sensação habitual de sobrecarga nas demandas e impossibilidade de completar o trabalho. Vivia a dificuldade de compreender os limites de minha atuação e, com isso, de colocar claramente um limite ao que me chegava.

Já quando ocupei espaços de diálogos com a gestão, no âmbito da pesquisa e nos movimentos sociais (com capacitações e controle social), pude participar de uma variedade de espaços que abordavam as políticas sociais, com contínuas reuniões que pautavam questões ligadas a diretrizes políticas, ações prioritárias, legislação, formação continuada, eixos de intervenção, monitoramento e avaliação de projetos e programas. Sentia-me valorizado, mas também tinha contínuas insatisfações com o resultado prático do trabalho. Faltava algo, como se a fome não fosse saciada. 
Ambos os lados do pêndulo são imprescindíveis para nossa profissão, e não é pelo fato de as oscilações existirem que essa realidade também não se processe de outras formas. Contudo, minha experiência foi trançada com muitos dados de realidade, e ecoa qualitativamente na maioria dos colegas com os quais convivi durante esse tempo. Além disso, alguns estudos consagrados corroboram essas ideias, demonstrando que há tanto sofrimento nas relações de trabalho (Dejours, 1987, 1999) como hiato das legislações e políticas públicas com a realidade do cotidiano em nossa sociedade (Dimenstein, 1993; Zaluar, 1994).

Com base nas considerações da dinâmica profissional feitas até aqui, devemos bailar como um pêndulo entre as extremidades exploradas acima, para que nossa ação seja nutritiva e em dose suficiente. A seguir, pontuo alguns questionamentos que podem servir de terreno para nosso exercício profissional.

\section{Questionamentos e considerações sobre nossas bases de atuação}

Quando falo em bases de atuação, refiro-me ao chão em que pisamos, que nos conecta à Terra, base para todos os humanos. Como é esse chão do psicólogo no SUAS? Quais aspectos se destacam do seu relevo, da sua composição mineral e orgânica? O que tem de potência produtiva?

Minha intenção não é dissecar essas perguntas nem encerrá-las, mas contribuir para a inteligibilidade de suas respostas a partir de aspectos que considero relevantes. Dependendo de como se mostra o terreno em que pisamos, podemos viver experiências escorregadias, áridas, úmidas ou firmes.

Por ora, vou ressaltar cinco elementos (separados aqui apenas por uma questão didática, mas que são imanentes e interagem continuamente) que compõem nossa base nas instituições onde são executadas as políticas públicas de assistência social, e que conferem características diversas a nosso terreno, dificultando ou potencializando o trabalho na superfície. Em cada um dos elementos, irei ressaltar aspectos pertinentes para fundamentar nossas raízes, dando estrutura à atuação.

A Figura 1 ilustra essa ideia. A princípio, observamos o terreno bruto (à esquerda e ao centro); em seguida, separamos alguns componentes que nos dedicaremos a comentar a seguir.
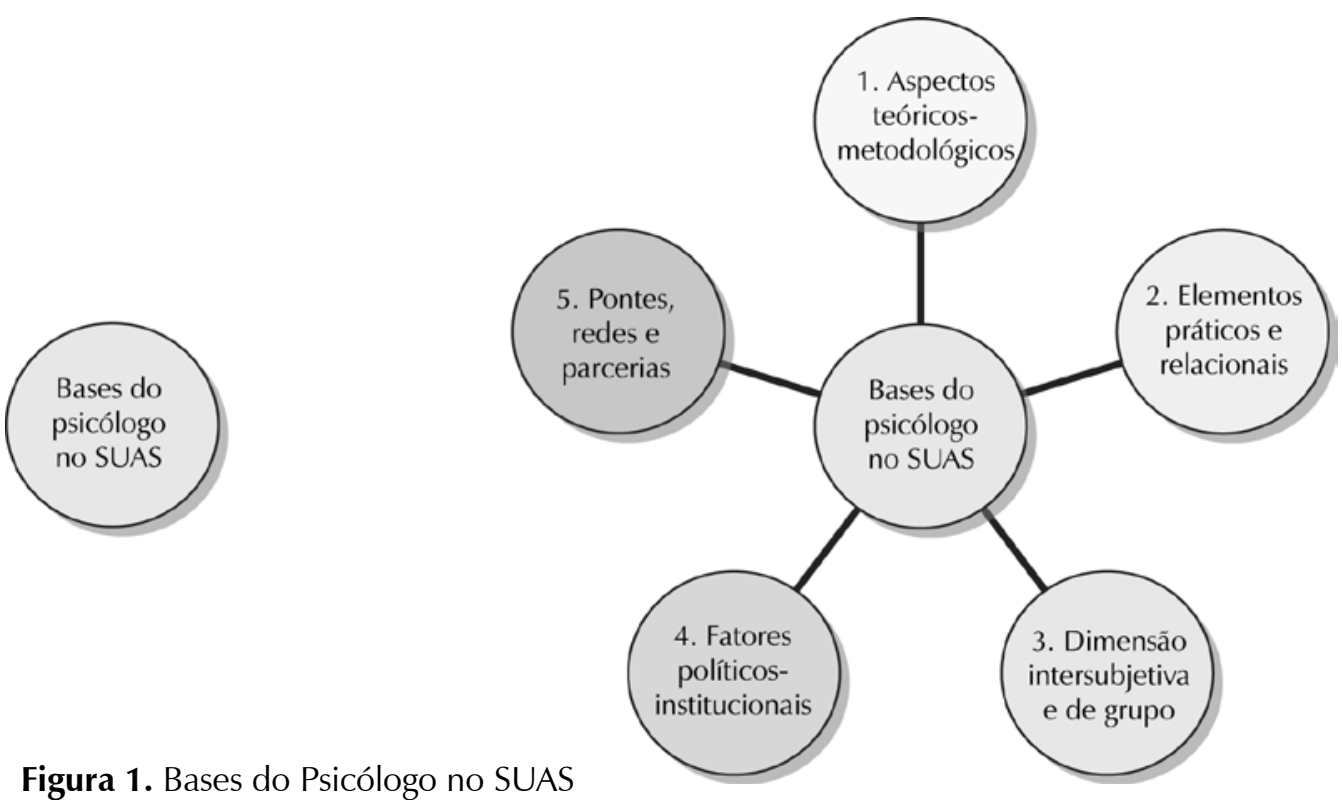

Figura 1. Bases do Psicólogo no SUAS 


\section{Aspectos teórico- metodológicos}

Enquanto estive atuando no SUAS, a maioria dos colegas de profissão com os quais convivi eram jovens, com poucos anos de prática, e aprendemos juntos que, nas ruas, praças públicas e outros espaços de livre trânsito, assim como nos domicílios, havia um espaço emergente para a ação profissional.

Alguns questionamentos que se referem à dimensão teórico-metodológica de nosso trabalho são pertinentes nesse cenário. Qual é o espaço institucional de reflexão e de cuidado do trabalho psicológico nômade? Há na instituição momentos de reflexão e de aprofundamento das possibilidades interventivas? Há espaço para aprendizagem teórico-prática sobre esse fazer que, historicamente, não compõe a formação dos psicólogos? Como lidar com a insegurança diante da nova proposta de atuação?

Acredito que espaços institucionais que se permitam tratar dessas indagações podem proporcionar fertilidade e qualidade ao trabalho psicológico, aprimorando continuamente uma prática profissional vanguardista que mantenha as raízes éticas e introduza a dinâmica contemporânea.

Nos lugares pelos quais passei, não foi possível implementar um espaço institucional sólido que privilegiasse esses elementos, diante das demandas emergentes no serviço. Em poucas ocasiões foi possível mergulhar nesses questionamentos. É perceptível a necessidade de fortalecer os pilares das indagações acima, que podem aparecer sob diversas formas no cotidiano institucional, impactando negativamente a prática no dia a dia devido à ausência de um posicionamento construído coletivamente entre os colegas.

\section{Elementos práticos e relacionais}

Um grande desafio é conseguir estabelecer um vínculo transformador com os usuários que historicamente constituíram amarras dolorosas em seus vínculos, impossibilitando, assim, relações de cuidado e segurança. Pessoalmente, percebi como foi desgastante estar continuamente disponível nesse trabalho.

Aqui há outra teia de questionamentos importante para reflexão da nossa prática: qual a condição humana de trabalho? Sabemos que as pessoas assistidas pelo serviço em geral têm histórias marcadas pela miséria social e emocional, com experiências traumáticas refinadas por horrores, sofrimento e desconfiança. Assim, qual o limite do contato humano que conseguimos estabelecer com nossos assistidos (na relação técnico-usuário)? Quais os limites e recursos subjetivos dos profissionais para lidar com tamanho sofrimento? Há suporte institucional para amparar experiências duramente consolidadas na subjetividade de nossos usuários?

No serviço, nas conversas entre profissionais, as experiências compartilhadas no acompanhamento de casos são férteis exemplos que enriquecem a reflexão; há um compartilhamento de frustrações e conquistas que encontram eco nos sentimentos que fortalecem a propagação das vivências em campo. Porém, esses espaços ainda são poucos, sedentos de maturação humana e de enriquecimento coletivo.

\section{Dimensões intersubjetivas e de grupo}

Outro elemento refere-se à condição de saúde dos profissionais que executam o serviço e o respectivo espaço de cuidado dentro da instituição. Por onde passei, ainda é precário o tratamento institucional. No Serviço de Educação de Rua, durante os seis primeiros meses de trabalho, é comum que os profissionais ingressem em um processo depressivo, e não apenas os psicólogos. 
Apesar de não haver estatísticas no serviço, todos os profissionais com os quais conversei - sejam assistentes sociais, pedagogos, educadores sociais - passaram por episódios moderados ou graves. Após esse período, havia uma reação defensiva e econômica, com uma grande quantidade de pedidos de exoneração, bem como a busca contínua por outras oportunidades, apontando claramente a redução do investimento energético e motivacional para o trabalho. Poucos colegas comentavam não terem vivenciado um episódio depressivo. E estes eram os que apresentavam contínuos problemas físicos (dores de coluna, enxaquecas, torcicolos, alergias e problemas respiratórios), corroborando a hipótese de somatização da carga ocupacional.

Qual o espaço institucional que privilegia a escuta dos profissionais em sua saúde integral, espaço onde se possam compartilhar as fortes emoções da lida cotidiana, oportunizando suporte afetivo para contrabalançar a carga de sofrimento trabalhada nas ruas?

Outro grupo de questionamentos que me parece também acompanhar a disposição interna para o trabalho refere-se ao nível de frustração pessoal dos profissionais. Como lidar com a frustração e a impotência em nossas ações? Como lidar internamente com a morte, prisão e/ou adoecimento severo de assistidos e os seus impactos em nosso fazer? Assim, espaços de acolhimento e reflexão sobre a frustração da equipe, com base nas expectativas da intervenção profissional, bem como os impactos na vida dos usuários, são imprescindíveis para propiciar um posicionamento crítico e afetivo diante das agruras do trabalho social.

Os que diariamente ocupam a linha de frente dos antipostais de nossas cidades conhecem a densidade dos sentimentos e as produções advindas. À primeira vista, achamos que o problema mais estrutural é a miséria financeira. Ao nos aproximarmos com mais cuidado da situação, penetrando - mesmo que limitadamente - na intimidade das vidas de pessoas em situação de rua, podemos observar outro tipo de miséria, de ordem afetiva: um flagelo emocional, uma individualidade dilacerada por experiências repetitivas de sofrimento, violência e dor.

Reich já havia descrito esse cenário como a peste emocional (1998), padronizando a repressão e a frustração como assujeitamento: "a supressão sexual torna-se instrumento essencial de escravização econômica" (Reich, 2004, p. 199). Assim, o(s) nó(s) subjetivo(s) construído(s) a partir da relação do sujeito com o mundo, a qualidade dos vínculos familiares, comunitários e sociais são frequentemente amarras maciças, da mesma intensidade que as barreiras materiais. Assim, por vezes, os assistidos permanecem no uso abusivo de drogas - em vez de seguirem o tratamento ofertado -; continuam longe dos laços familiares - em vez de reverem as experiências de privação, dor e satisfação -, ou ainda, permanecem no cotidiano ocioso - em vez de ingressarem em atividade produtiva.

Exemplos ilustrativos são os casos de pessoas em situação de rua que retiram seus documentos e os perdem ou os trocam por alguma porção de drogas, e repetem essa postura mecanicamente por três, quatro, cinco vezes.

Um grande desafio se nos apresenta: construir vínculos diferentes em relações transformadoras, que possam semear, na intimidade dessas pessoas, sentimentos de segurança, prazer, cuidado e potência.

Nossa intenção com estes comentários não é reduzir o sofrimento à responsabilização individual, tampouco reforçar a dialética da sobredeterminação das coisas, mas sim, reforçar a simultaneidade das misérias afetivas e sociais, ressaltar a expertise do profissional de Psicologia, que se configura no caminho fértil para um exercício singular, sem se perder nas inúmeras demandas de várias ordens, enunciadas cacofonicamente, ora por sujeitos sedentos de amparo, ora 
pelas diversas políticas sociais carentes de resultados. Não raro nossa equipe de trabalho tropeçava descuidadamente nessas demandas, executando tarefas que escapavam às nossas atribuições e que nos distanciavam da ação singular, que efetivamente trazia contribuição autêntica para o cenário social.

\section{Fatores político-institucionais}

Continuamente, percebi que a Psicologia é essencial para o desenvolvimento do trabalho com a população nas políticas sociais; no entanto, compreendo que esse trabalho ainda sinaliza muitos limites em relação a seus objetivos últimos. Se, por um lado, há o potencial da atuação micropolítica na emergência do desejo e nas possibilidades de mudança, por outro, são inegáveis as influências macrossociais dos modos capitalistas de relacionamento, assim como seus impactos sobre a manutenção da miséria - muitas vezes duplamente reforçada na relação técnico-usuário mecanicamente orientada por interesses descuidados.

Nesse sentido, não é raro perceber que, nas relações institucionais, há marcas precisas do desgaste humano, expresso na balança injusta dos interesses políticos e capitais. As dificuldades, em diversas proporções, atingem a remuneração profissional aquém das condições de uma manutenção dotada de qualidade de vida; há ausência ou insuficiência de recursos e de equipamentos operacionais para o trabalho (transporte, computador, vestimenta adequada, etc).

Assim, pelo processo histórico do serviço público, bem como pela compreensão crítica da implantação de outros sistemas de prestação de serviço universal (a exemplo do SUS), sabemos que há uma contínua luta para a consolidação do serviço de qualidade e para a garantia de recursos ideais destinados à execução do trabalho.

Aqui podemos então elencar um grupo de questionamentos a fim de qualificar a atuação do psicólogo no SUAS: qual o espaço institucional para tratar das condições de trabalho, das possibilidades reais, dos projetos futuros? Como promover a criatividade necessária para a atuação na adversidade dos desafios cotidianos, com base na contínua luta pela institucionalização de serviços e de programas em processo de normatização das práticas? Há a possibilidade de se conversar sobre a projeção das dificuldades institucionais, das adversidades das condições de trabalho e de seu impacto na qualidade do serviço, nos usuários, na subjetividade do profissional?

Esses aspectos devem ser entendidos como discussão necessária nos espaços sindicais e de controle das políticas públicas (a exemplo dos Conselhos de Assistência Social); no entanto, parte desses questionamentos deve ser integrada ao nível dos afazeres institucionais cotidianos, para que a realidade possa consolidar um exercício íntegro do profissional e para que este possa pactuar com os desafios da consolidação da cidadania, lidando com clareza e seriedade diante dos limites e possibilidades concretos em sua função sem tabus, jogos políticos ou manipulação de interesses por pressão social, mas com a simplicidade das tramas humanas e dos arranjos necessários para a sua superação.

Tais aspectos marcam expressivamente nosso trabalho cotidiano. Não pude acompanhar a institucionalização de um lugar privilegiado para aprofundar esses questionamentos, mas posso dizer que esses elementos sempre se fizeram presentes nas reuniões dos serviços de que participei. Quando houve a possibilidade de compartilhar sentimentos e experiências, tivemos uma percepção coletiva de dificuldade e necessidade de cuidado em nossa condição de trabalho.

Aqui há um grande desafio para o profissional de Psicologia: ter noção crítica da contradição do como escutar, se não se é escutado? Descobrimos cedo em nosso trabalho que a subjetividade só opera com práticas por nós 
aprendidas e interiorizadas. Dessa forma, garantir uma escuta saudável do público atendido implica garantir espaços verdadeiros de escuta na instituição.

\section{Pontes, redes e parcerias}

Pensar em redes, pontes e parcerias no trabalho é indispensável. A maioria das políticas sociais e de garantia de direitos reforça a necessidade da articulação de diversos equipamentos e segmentos para conferir-lhes legitimidade. Apesar de algumas legislações (a exemplo do Estatuto da Criança e do Adolescente) enfatizarem a importância de toda uma rede, na prática, ainda caminhamos para a sua real efetivação. Inúmeras experiências que circulam o cotidiano do trabalho nos equipamentos da assistência evidenciam choques e abismos nas relações interinstitucionais e intersetoriais, demonstrando objetivamente a distância das agendas políticas quanto às prioridades de ação e quanto à visão de sujeito e de mundo. São situações que nos colocam continuamente na frente de batalha, nas quais nem sempre temos as armas necessárias para instaurar a solidariedade necessária às parcerias efetivas.

Diante disso, alguns questionamentos se colocam: qual a base real de sustentação para nosso trabalho com os usuários, no fomento da autonomia em suas trajetórias de vida? Assim como pode faltar o chão para suportar experiências de profundo sofrimento, também pode faltar apoio para auxiliar os passos dos sujeitos em seus desejos.

Quais as reais condições das redes sociais que contribuem efetivamente para a instauração da cidadania aos usuários? O que, das leis, é de fato exequível? Há posicionamentos demarcados de quais situações demandar amparo desses equipamentos? Ou ainda, há ações que apontam resultados efetivos nas atividades colaborativas entre os serviços? Há espaços nas instituições para amadurecer as participações do trabalho coletivo, das ações em rede no atendimento ao público? Há integração com outras políticas públicas? Tais dilemas ético-políticos nos envolvem cotidianamente, instando opções criativas de solidariedade e apoio, por um lado, e de confrontos sequenciais com os limites dos aparatos públicos por outro. Mesmo diante de significativas melhoras, ainda nos deparamos com abismos e lacunas que sentenciam o descaso com muitas vidas. Esses são alguns questionamentos que podem iluminar as delicadas nuances de nosso exercício profissional para a atenção integral na assistência social.

Como dito no início do texto, longe de encerrar perguntas, faço uso de minha aventura subjetiva trançada pelos encontros e desencontros com SUAS para enunciar alguns elementos que podem alimentar o debate da Psicologia nesse cenário e fortalecer o exercício profissional, adubando outras superfícies para uma finalidade comum: o desenvolvimento humano e a justiça social. No título deste artigo, refiro-me à dor e à delícia, pois estas linhas só poderiam ser escritas embaladas por minhas memórias afetivas dos choros e sorrisos que emergiram espontaneamente no encontro com tantas vidas, ensinando-me respeito, cumplicidade e solidariedade.

Por fim, espero ter encorajado os companheiros de profissão a instaurar um laço ético que valorize a dignidade de sua experiência e de suas emoções, bem como suas indagações mais simplistas e essenciais, potência vital para seus atos diários. A complexidade da experiência, a trama subjetiva do fazer psicológico na política social é recheada de desafios práticos e posicionamentos teóricometodológicos, em que simples posturas, atitudes e questionamentos podem ofertar qualificação e fortalecimento para nossa atuação. 


\section{Alexandre Franca Barreto}

Mestre em Antropologia pela Universidade Federal de Pernambuco, Professor Assistente da Universidade Federal do Vale do São Francisco, Recife - PE - Brasil.

E-mail alexandre.barreto@univasf.edu.br

\section{Endereço para envio de correspondência:}

Universidade Federal do Vale do São Francisco (UNIVASF), Colegiado de Psicologia. Av. José de Sá Maniçoba, S/N - Centro, Petrolina - PE - Brasil CEP 56304-917

Recebido 3/5/2010, 1aㅡ Reformulação 7/10/2010, 2a - Reformulação 24/11/2010 Aprovado 22/12/2010

Barreto, A. F. (2007). Gênero, corpo, emoção e medidas socioeducativas. Uma aproximação da violência urbana. Dissertação de mestrado, Programa de Pós-Graduação em Antropologia, Universidade Federal de Pernambuco, Recife, PE.

Bock, A. M. B. (1999). A psicologia a caminho do novo século: identidade profissional e compromisso social. Estudos de Psicologia, 4(2), 315-329.

Bock, A. M. B. (Ed.). (2003). Psicologia e o compromisso social. São Paulo: Cortez

Boff, L. (1999). Saber cuidar: ética do humano - compaixão pela Terra. Petrópolis, RJ: Vozes.

Conselho Federal de Psicologia. Conselho Federal de Serviço Social. (2007). Parâmetro para atuação de assistentes sociais e psicólogos(as) na Política de Assistência Social. Brasília, DF: Autor

Dejours, C. A. (1987). A loucura no trabalho. Estudo da psicopatologia do trabalho. São Paulo: Oboré Editorial.

Dejours, C. (1999). A banalização da injustiça social. Rio de Janeiro: Editora da FGV.

Dimenstein, G. (1993). Cidadão de papel: a infância, a adolescência e os direitos humanos no Brasil. São Paulo: Ática.

Dimenstein, M. (2001). O psicólogo e o compromisso social no contexto da saúde coletiva. Estudos de Psicologia, 6(2), 57-63.

Dutra, E. (2004). Considerações sobre as significações da psicologia clínica na contemporaneidade. Estudos de Psicologia, 9(2), 381-387.
Guizardi, F. L., \& Pinheiro, R. (2008). Quando dádiva se transforma em saúde: algumas questões sobre a integralidade e o cuidado nas relações entre sociedade e estado: In R. Pinheiro, \& R A. Mattos (Orgs.), Cuidado: as fronteiras da integralidade (pp. 39-58). Rio de Janeiro: CEPESC/UERJ, ABRASCO.

Lowen, A. (1984). Prazer: uma abordagem criativa da vida. São Paulo: Summus.

Mazza, J. (2009). Relatório final de estágio supervisionado. Departamento de Psicologia, Universidade Federal de Pernambuco, Recife, PE.

Ministério do Desenvolvimento Social e Combate à Fome Secretaria Nacional de Assistência Social. (2004). Política Nacional de Assistência Social (PNAS). Brasília, DF.

Reed-Danahay, D. E. (1997). Introduction. Auto/ethnography: Rewriting the self and the social. New York: Berg.

Reich, W. (1998). Escuta Zé-Ninguém. São Paulo: Martins Fontes.

Reich, W. (2004). A função do orgasmo. São Paulo: Brasiliense.

Rolnik, S. (1997). Clínica nômade. In Equipe de Acompanhantes Terapêuticos do Hospital-dia A Casa (Org.), Crise e cidade: acompanhamento terapêutico (pp.83-97). São Paulo: EDUC.

Silva, É. R. da. (2001). Psicologia clínica, um novo espetáculo: dimensões éticas e políticas. Psicologia: Ciência e Profissão, 21(4), 78-87.

Spry, T. (2001). Performing autoethnography: An embodied methodological. Praxis Qualitative Inquiry, 7(6), 706-732.

Zaluar, A. (1994). A máquina e a revolta: as organizações populares e o significado da pobreza ( $2^{a}$ ed.). São Paulo: Brasiliense. 